\title{
Recycling of solid waste material in Hong Kong: I. Properties of modified clay mineral waste material and its application for removal of cadmium in water
}

\author{
Y. N. Jiang ${ }^{1}$, H. D. Ruan ${ }^{1 *}$, S. Y. Lai ${ }^{2}$, C. H. Lee ${ }^{1}$, C. F. Yu ${ }^{1}$, Z. Wu ${ }^{1}$, X. Chen ${ }^{1}$, S. He $^{1}$ \\ ${ }^{1}$ Environmental Science Program, Division of Science and Technology, United International College, Beijing Normal University-Hong \\ Kong Baptist University, Zhuhai, Guangdong Province, 519085, P. R. China \\ ${ }^{2}$ Department of Chemistry, Hong Kong Baptist University, Kowloon Tong, Hong Kong
}

\section{Email address:}

hruan@uic.edu.hk (H. D. Ruan)

\section{To cite this article}

Y. N. Jiang, H. D. Ruan, S. Y. Lai, C. H. Lee, C. F. Yu, Z. Wu, X. Chen, S. He. Recycling of Solid Waste Material In Hong Kong: I. Properties of Modified Clay Mineral Waste Material and its Application for Removal of Cadmium In Water. Earth Science. Vol. 2, No. 2, 2013, pp. 40-46. doi: 10.11648/j.earth.20130202.13

\begin{abstract}
Large quantities of solid waste are disposed to landfill sites in Hong Kong each year and these landfill sites will be filled within five years. Recycling of solid waste material has become a very urgent task and evaluation of its application in environmental remediation has been functioned recently. Mineral-containing waste material, which is one of the common solid waste components to be disposed to landfill sites in Hong Kong, was used to produce the modified clay mineral waste material (MCMWM) for removal of cadmium (Cd) in water. The physical, chemical and mineralogical properties of MCMWM related to Cd adsorption were investigated using scanning electron microscopy (SEM) coupled with energy dispersive X-ray analysis (EDX), X-ray diffraction (XRD), Fourier transform infrared spectroscopy (FTIR), BET specific surface area (SSA) and pore size distribution (PSD) measurements, and inductively coupled plasma optical emission spectroscopy (ICP-OES). The particle size of MCMWM ranged from less than a few to tens of micrometers, and the particles had rough surface and structural defects. Specific surface area was $5.6 \mathrm{~m}^{2} / \mathrm{g}$, with different types of external and internal pores being observed. The minerals in MCMWM were mainly 2:1 clay minerals. Smectite, illite, chlorite, feldspars, quartz, and calcium hydroxide were detected. Heavy metals including arsenic, cadmium, chromium, mercury and lead detected in MCMWM were much lower than the maximum allowed level for each kind of heavy metal based on the Dutch Standard that has been used worldwide. Cadmium adsorption by MCMWM was very rapid in solid/liquid interface as up to $90 \%$ of $\mathrm{Cd}^{2+}$ can be adsorbed within half hour of reaction. The amount of $\mathrm{Cd}^{2+}$ adsorbed increased but the rate of adsorption decreased with increasing concentration of $\mathrm{Cd}^{2+}$ in solution. $\mathrm{The}^{2+}$ adsorption was related to the surface structure and chemistry, including SSA, PSD, surface defect, charge and bonding in MCMWM.
\end{abstract}

Keywords: Adsorption, Heavy Metals, Modified Clay Mineral Waste Material (MCMWM), Pore Size Distribution (PSD), Specific Surface Area (SSA), Cadmium (Cd)

\section{Introduction}

Solid waste treatment and disposal have experienced troublesome in Hong Kong due to the limit in landfill areas. Recycling of solid waste materials has been functioned in the past ten years. The ratio of recycling (through public fill reused or received at public fill reception facilities) to disposal increased each year. Construction waste materials, for instance, one of the major components up to $30 \%$ in total solid waste, have been recycled over $80 \%$ since 2006 . However, 1.3 million tones of construction waste materials and more than 5.5 million tones in total of solid waste materials are still disposed to landfill sites in Hong Kong each Year [1]. Thus there is large potential to increase recycling of solid waste materials with focuses on their multi-functional applications. It is our first attempt to use mineral-containing solid waste material to produce the modified clay mineral waste material (MCMWM) through physical and chemical modifications. The MCMWM has been applied for the removals of heavy metals and toxic organic compounds in water and air, and the remediation of contaminated soils. The experimental results obtained are expected to be published in a series. Cadmium, as one of 
the top five toxic heavy metals, is therefore chosen to deal with its adsorption by MCMWM in this study.

Cadmium (Cd) exists commonly in the forms of $\mathrm{CdS}$, $\mathrm{CdCO}_{3}, \mathrm{CdSO}_{4}$, and $\mathrm{CdO}$ in the environment, which can be commonly found in water, sediment and soil. Cadmium is one of the heavy metals that can be bio-accumulated in aquatic systems through hydrophytic organisms. If $\mathrm{Cd}$ enters into human bodies, liver and kidney will be affected [2]. Long term exposure to $\mathrm{Cd}$ could lead to chronic toxic renal injury. A recent report indicated that the average daily intake of $\mathrm{Cd}$ by a resident in Guangdong provinces of China was about $65 \mu \mathrm{g} / \mathrm{kg}$ [3], which exceeded the $60 \mu \mathrm{g} / \mathrm{kg}$ of the Allowable Daily Intake (ADI) of Cd set by WHO/FAO for a $60 \mathrm{~kg}$ person. This implies potential environmental hazards in the Pearl River Delta region of China. Long-term exposure to high-level $\mathrm{Cd}$ may cause anaemia, hypertension, kidney damage and even itai-itai disease, as exemplified in the event happened in Japan in 1970s due to high-intake of $\mathrm{Cd}$ from rice [4-6]. The global $\mathrm{Cd}$ consumption in the last two decades has shown a general trend of a steep increase. Cadmium enters the environment through a variety of industrial operations, and is an impurity found in zinc, by-products from mining, smelting, electroplating, pigment, and plasticizer production. Cadmium emissions come from burning of fossil fuels. Cadmium makes its way into water supplies as a result of deterioration of galvanized plumbing, industrial waste or fertilizer contamination [7].

The 2:1 clay minerals consisting of interlayers may have high adsorption ability because of the charges on surface, structural configuration, and high surface area $[2,8]$. The adsorption can be selective and non-selective [2, 9-10]. In terms of physical properties, the $2: 1$ clay mineral has negative charges on the surface, which can attract positively charged $\mathrm{Cd}$. This kind of interaction between the solid surface and adsorbate is non-selective adsorption that belongs to the electrostatic interaction $[2,8]$. The selective adsorption is one kind of chemical adsorption, which can occur through surface bonding and affinitive site. Selective adsorption takes place only between certain adsorbents and adsorptive species when the surface is free of adsorbed molecules. The adsorption phenomenon can also result in the sharing of electrons between the adsorbate and surface of solid. Surface structure has been reported to dominate the capacity of adsorption [10-11]. Cadmium adsorption depends on $\mathrm{pH}$, redox potential, chemical nature of the metal species, stability of $\mathrm{Cd}$ complexes, binding power of the functional groups and ionic strength of solutions and competing ions [2, 9, 12-15].

Some aspects of the chemical behavior of $\mathrm{Cd}$ in soils can be explained by the hard-soft Lewis acid-base principle [9]. Cadmium is a soft Lewis acid and easily reacts and forms complexes with soft Lewis bases such as chloride and hydroxyl groups. Such surface charge compensation takes place through adsorption of cations, largely in the forms of outer sphere complexes, and non-preferential adsorption of counter ions in the diffuse layer [2, 9-10]. Two types of adsorption sites have been reported: 1) low-capacity, high-affinity sites for low concentrations of $\mathrm{Cd}$; and 2) lower-affinity but higher-capacity sites for higher concentrations [7]. The substantial differences in adsorption preferences for various cations exhibited by different clay minerals may be traced to the location and the extent of the isomorphous substitution [10-11], and to the hardness of the Lewis base sites that result [2]. At extremely high $\mathrm{Cd}$ concentrations, precipitates of $\mathrm{Cd}$ phosphates and carbonates could be expected to form.

Because clay is classified as less than $2 \mu \mathrm{m}$ in equivalent spherical diameter (e.s.d.), it contains colloids ( $1 \mathrm{~nm}$ to $1 \mu \mathrm{m})$ and is the most active fraction in the soil and sediment. Clay is highly important to environmental significance because of its large surface areas and reactive surfaces [2, 10-11]. In this work, modified clay mineral waste material (MCMWM) was investigated to study its physical, chemical and mineralogical properties, in particular its surface and structure properties in relation to its capacity and potential application in adsorption of $\mathrm{Cd}$.

\section{Experimental}

The modified clay mineral waste material (MCMWM) produced commercially through physical and chemical processes was a mixture of minerals mainly from rocks and soils. Illite, smectite, feldspar, chlorite, quartz, calcium hydroxide and some other oxyhydroxides were found in MCMWM.

\subsection{Characterization of MCMWM}

The mineral compositions of MCMWM were identified by X-ray diffraction (XRD). Fourier transform infrared spectroscopy (FTIR) was used to detect surface structure. The particle size and shape, and elemental contents of MCMWM were examined using scanning electron microscopy (SEM) coupled with electron dispersive X-ray analysis (EDX). The measurements of specific surface area (SSA) and pore size distribution (PSD) were carried out at a BET apparatus using nitrogen absorption [16]. The heavy metal contents in MCMWM were determined using a modified $\mathrm{HNO}_{3}-\mathrm{HClO}_{4}$ method for digestion, and a Varian 720-ES Inductively Coupled Plasma Optical Emission Spectroscopy (ICP-OES) for elemental determination.

\subsection{Adsorption of Cd2+ on MCMWM}

A stock $\mathrm{Cd}^{2+}$ standard solution $(1000 \mathrm{mg} / \mathrm{L})$ was firstly prepared by dissolving $3.0689 \mathrm{~g}$ of $\mathrm{Cd}\left(\mathrm{NO}_{3}\right)_{2} \cdot 6 \mathrm{H}_{2} \mathrm{O}$ in 1000 $\mathrm{ml}$ of DI water. The adsorption of $\mathrm{Cd}^{2+}$ experiment was then carried out in the following procedures. Various concentrations of $\mathrm{Cd}^{2+}$ solution, 20, 40, 80 and $200 \mathrm{mg} / \mathrm{L}$ were firstly prepared by dilution using the $1000 \mathrm{mg} / \mathrm{L}$ stock solution. Then $0.1 \mathrm{~g}$ (accurate to $0.0001 \mathrm{~g}$ ) subsample of MCMWM was placed into a $50 \mathrm{ml}$ tube and $20 \mathrm{ml}$ of DI water was added to wet the solid sample. The $\mathrm{pH}$ of the solution was adjusted to 6 by adding either $\mathrm{HCl}$ or $\mathrm{NaOH}$ solution. Twenty-five milliliter of $\mathrm{Cd}^{2+}$ solution of 20, 40, 80 , or $200 \mathrm{mg} / \mathrm{L}$ was added into each tube containing the subsample of MCMWM. More DI water was added to 
make up the volume to the mark of $50.00 \mathrm{ml}$. The tubes were capped and placed in a horizontal shaker and shaken at a speed of $200 \mathrm{rpm}$ at $25^{\circ} \mathrm{C}$ for $0.5 \mathrm{hr}$. After shaking, the samples were filtered to obtain clear supernatants. The concentrations of $\mathrm{Cd}^{2+}$ in the supernatants after adsorption were determined using a Varian 720-ES Inductively Coupled Plasma Optical Emission Spectroscopy (ICP-OES). The loss of $\mathrm{Cd}^{2+}$ from the solution was regarded as the amount of Cd adsorbed.

\section{Results and Discussion}

\subsection{Elemental Properties of MCMWM}

The results of EDX showed that MCMWM consisted mainly of silica, aluminum, calcium, carbon, and oxygen, with other elements including potassium, sodium, magnesium, sulfur and iron (Table 1). The large amounts of calcium, silica and aluminum indicated that the minerals in MCMWM could be silicate-aluminum and calcium-containing minerals. The high content of calcium could be related to a number of minerals and compounds, such as Ca-feldspar and calcium hydroxide. A medium amount of iron was found in the samples but iron oxides were hardly detected using XRD and FTIR. The reason for this may be due to iron being present in the mineral structure, but not in the forms of iron oxides. A medium amount of potassium might come from K-feldspar. The minerals in MCMWM consist of fewer weathered materials but more rock or parent materials. The high carbon and oxygen contents might be attributed either to organic matter, or to certain amount of carbonate minerals present in the sample. The majority of oxygen was believed to be in the structure by bonding to the metals or silica, and be present as hydroxyls on a crystal surface. These types of bonds are indicated by the FTIR vibrations (Figure 1), and are consistent with the findings of Ruan, et al. [17].

Table 1. Elemental Composition of MCMWM

\begin{tabular}{llllllllllll}
\hline Element & $\mathrm{C}$ & $\mathrm{O}$ & $\mathrm{Na}$ & $\mathrm{Mg}$ & $\mathrm{Al}$ & $\mathrm{Si}$ & $\mathrm{S}$ & $\mathrm{K}$ & $\mathrm{Ca}$ & $\mathrm{Fe}$ & Total \\
\hline Wt. \% & 8.0 & 46.2 & 0.7 & 0.7 & 4.4 & 15.4 & 0.6 & 2.0 & 19.3 & 2.7 & 100.0 \\
At. \% & 13.5 & 58.7 & 0.6 & 0.6 & 3.3 & 11.1 & 0.4 & 1.0 & 9.8 & 1.0 & 100.0 \\
\hline
\end{tabular}

Wt. --- Mass weight, At. --- Atomic weight

\subsection{Mineral Properties of MCMWM}

The powder X-ray diffraction (XRD) results of MCMWM show that smectite, illite, chlorite, feldspars, quartz, and calcium hydroxide were detected (Table 2). The feldspars were Na-feldspar, K-feldspar and Ca-feldspar. Calcium hydroxide diffraction peaks were obviously detected showing d-values at 1.937 and $1.803 \AA$, although the d-values at 4.973 and $2.645 \AA$ were overlapped by diffraction spacings from muscovite. Because most minerals present in MCMWM were 2:1 clay minerals (Table 2 ), these minerals usually carry negative charges that can provide affinity and selectivity in adsorbing cations onto their surfaces. This was in agreement with previous findings [2], [18], that the adsorption of $\mathrm{Cd}^{2+}$ onto 2:1 clay mineral surfaces was affected by charges.

Table 2. XRD Identification of Minerals in MCMWM

\begin{tabular}{|c|c|c|}
\hline Mineral/chemical comp. & d-value $(\AA)$ & $\begin{array}{l}\text { Intensity ratio }\left(\mathrm{I} / \mathrm{I}_{0}\right) \\
(\%)\end{array}$ \\
\hline \multicolumn{3}{|l|}{ Smectite } \\
\hline Montmorillonite & 14.669 & 15 \\
\hline \multirow{3}{*}{$\begin{array}{l}\text { Illite } \\
\text { Muscovite } \\
\text { Mica }\end{array}$} & & \multirow{3}{*}{$\begin{array}{l}29,17,22 \\
10,11\end{array}$} \\
\hline & $\begin{array}{l}4.9 / 3, \quad 3.05 \%, \\
2.645\end{array}$ & \\
\hline & $3.738,3.570$ & \\
\hline \multirow{5}{*}{ Feldspar } & 4.295 & 15 \\
\hline & 3.318 & 16 \\
\hline & 3.271 & 66 \\
\hline & 3.179 & 13 \\
\hline & 3.155 & 13 \\
\hline Chlorite & $7.201,4.771$ & 21,12 \\
\hline Quartz & $4.295,3.368$ & 15,100 \\
\hline Calcium hydroxide & $\begin{array}{l}4.973, \quad 2.645, \\
1.937,1.803\end{array}$ & $29,22,13,11$ \\
\hline
\end{tabular}

\subsection{Fourier Transform Infrared Spectroscopy of MCMWM}

A very strong and broad vibration band between 1200 and $900 \mathrm{~cm}^{-1}$ was the multi-vibration frequencies from various minerals and chemical compounds (Figure 1). For instance, the band at $1080-991 \mathrm{~cm}^{-1}$ was assigned to illite-smectite mixed-layer mineral, $1080-1072 \mathrm{~cm}^{-1}$ and $1025-1010 \mathrm{~cm}^{-1}$ to illite, $1040-1015 \mathrm{~cm}^{-1}$ to montmorillonite of the smectite group, and 1032-1021 cm $\mathrm{cm}^{-1}$ and 1000-991 $\mathrm{cm}^{-1}$ to muscovite of the illite group. The band at $982 \mathrm{~cm}^{-1}$ was assigned to chlorite and $1092 \mathrm{~cm}^{-1}$ to $\mathrm{Ca}(\mathrm{OH})_{2}$. Another band of $\mathrm{Ca}(\mathrm{OH})_{2}$ was shown at $1450 \mathrm{~cm}^{-1}$. Vibration at $1640 \mathrm{~cm}^{-1}$ was also assigned to muscovite. The feldspar group exhibited vibration frequency around $798 \mathrm{~cm}^{-1}$. The bands at $2917 \mathrm{~cm}^{-1}$ and $2850 \mathrm{~cm}^{-1}$ in high vibration number regions might be due to the stretching vibration resulting from surface adsorbed water, and the bands at $2359 \mathrm{~cm}^{-1}$ and $2341 \mathrm{~cm}^{-1}$ might be attributed to the surface $\mathrm{OH}$ bending.

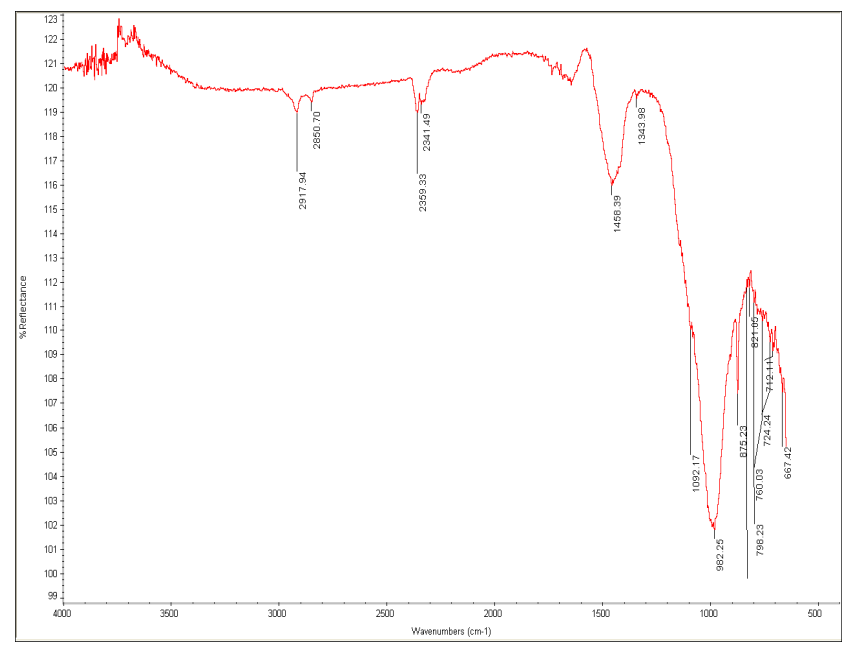

Figure 1. FTRI Spectrum of MCMWM. 


\subsection{Surface Properties of MCMWM}

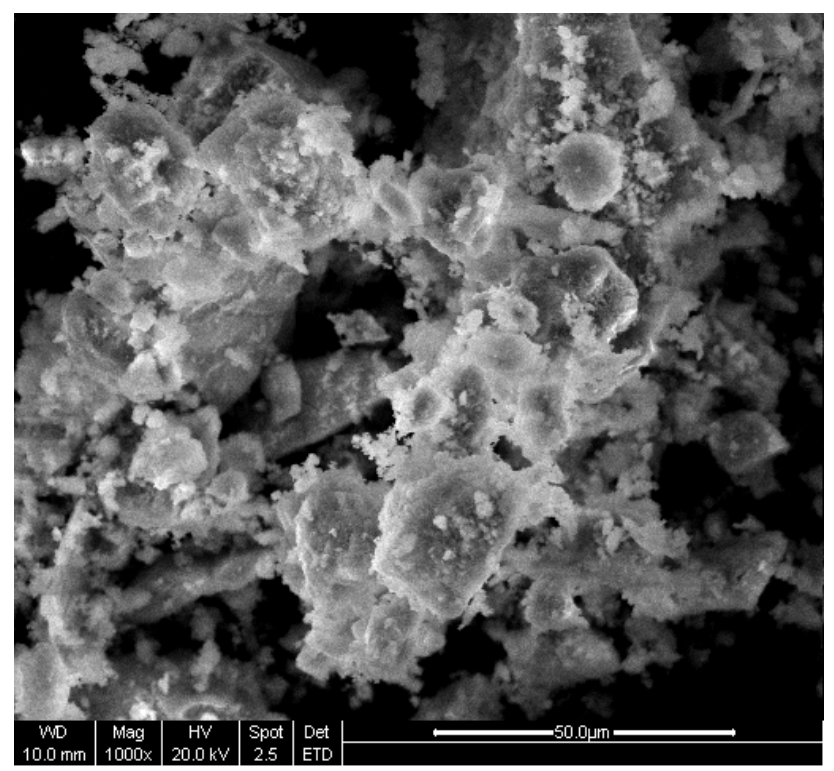

Figure 2. Scanning electron micrograph showing various particle size, shape and pore of $M C M W M$.

Various particle sizes and shapes were observed from electron microscopic images (Figure 2). This finding showed that the process of modification produced particles of size mainly from less than a few and around 20 micrometers; some were even smaller than 1 micrometer. Rough surfaces with different shapes were clearly seen from the micrograph. Note that the particles with various sizes and different shapes might produce interparticle voids of various sizes. Some internal pores could be formed during the process of modification (Figures 2 and 4). Both external and internal pores provided adsorption sites to adsorbates although the mechanisms and kinetics of adsorption for these two types of pores were different $[10,19-21,22]$. In addition, structural and surface defects were formed during modification process. The defects provided adsorption sites and bonds to attract cations to settle. A research on adsorption and desorption mechanism and kinetics by Ruan and Gilkes [10] indicated that a rough surface of minerals with defects provided much more adsorption sites to adsorbates and the capacity of adsorption thus increased by a few times.

\subsection{Specific Surface Area and Pore Structure of MCMWM}

The nitrogen adsorption and desorption isotherms of MCMWM are shown in Figure 3. Specific surface area (SSA) measured by BET compartment and calculated using the first five linear points from nitrogen adsorption isotherm was $5.6 \mathrm{~m} 2 / \mathrm{g}$. The SSA, pore size distribution (PSD) (Figure 4) and pore shape were of importance to cation and anion adsorption onto MCMWM. Previous research had found that modification might lead to the development of a porous internal fabric in crystals [11, 22-26]. The adsorption-desorption isotherms exhibited a H4 type hysteresis loop (Figure 3), which could be attributed mainly to the presence of slit-shaped mesopores. As shown in
Figure 4, prominent slit-shaped pores with size in the range of 3.7-4.0 nm were observed. The broad pore range above $10 \mathrm{~nm}$ could be due to interparticle voids. A SSA of 5.6 $\mathrm{m}^{2} / \mathrm{g}$ was obtained for MCMWM and such a SSA value was good enough to provide pores as adsorption sites for the reactions between adsorbents and adsorbates. As suggested earlier from the scanning electron micrographs, the rough surfaces having external and internal pores made MCMWM satisfactory in the application for heavy metal removal.

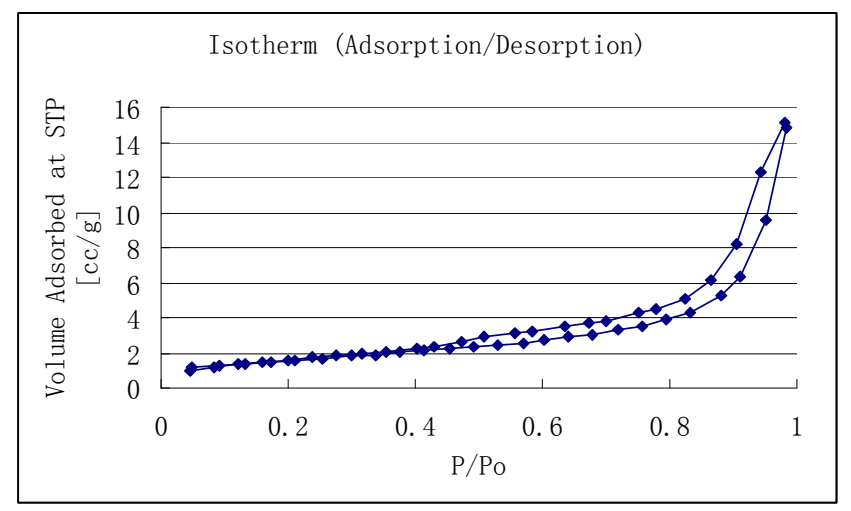

Figure 3. Nitrogen adsorption/desorption isotherms of MCMWM

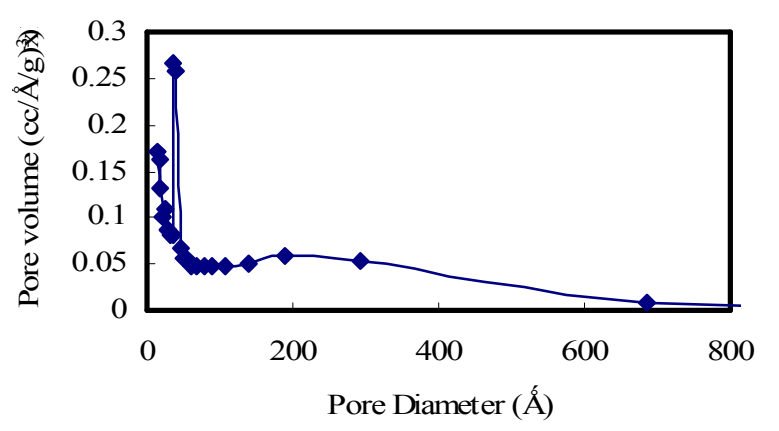

Figure 4. Pore size distribution of the MCMWM determined from the desorption branch of the adsorption isotherm (pore volume at $10^{-3}$ scale).

\subsection{Heavy Metals in MCMWM}

Table 3. Heavy Metal Contents in MCMWM Compared to Dutch Standard

\begin{tabular}{|c|c|c|c|c|}
\hline Heavy metal & $\begin{array}{l}\text { Concentration } \\
\text { in sample } \\
(\mathrm{mg} / \mathrm{kg})\end{array}$ & $\begin{array}{l}\text { Dutch } \\
(\mathrm{mg} / \mathrm{kg})\end{array}$ & standard & for soil \\
\hline & & A & B & $\mathrm{C}$ \\
\hline Arsenic (As) & 4.13 & 20 & 30 & 50 \\
\hline Cadmium (Cd) & 1.12 & 1 & 5 & 20 \\
\hline Chromium (Cr) & 22.43 & 100 & 250 & 800 \\
\hline Mercury (Hg) & $<1.00$ & 0.2 & 2 & 10 \\
\hline Lead $(\mathrm{Pb})$ & 27.58 & 50 & 150 & 600 \\
\hline
\end{tabular}

Chemical analysis of heavy metals in MCMWM was based on the USEPA method 3050B. The concentrations of five heavy metals are listed in Table 3, indicating that 
arsenic was $4.13 \mathrm{mg} / \mathrm{kg}$, cadmium $1.12 \mathrm{mg} / \mathrm{kg}$, chromium $22.43 \mathrm{mg} / \mathrm{kg}$ and lead $27.58 \mathrm{mg} / \mathrm{kg}$, respectively. Mercury was lower than the detection limit, thus it was reported as $<1.00 \mathrm{mg} / \mathrm{kg}$. The results of chemical analysis of the five heavy metals indicated that none of them exceeded the maximum allowed limits of the Dutch Standard (Table 3). The levels of four of them were lower than those of Level A (the lowest levels of the Dutch Standard). Only cadmium was slightly over between Levels A and B, compared 1.12 $\mathrm{mg} / \mathrm{kg}$ with $1.0 \mathrm{mg} / \mathrm{kg}$ (Level A of Dutch Standard), but it was much less than that of Level B $(5.0 \mathrm{mg} / \mathrm{kg})$ and even level C (20 mg/kg). Thus the MCMWM was considered to be safe and satisfactory for the use as adsorbent for environmental remediation.

\subsection{Adsorption of Cd2+ Relating to Properties of MCMWM}

The amounts of $\mathrm{Cd}^{2+}$ adsorbed by MCMWM from solutions with various initial $\mathrm{Cd}^{2+}$ concentrations are shown in Table 4 and Figure 5. The adsorption capacity and factors affecting $\mathrm{Cd}^{2+}$ adsorption are discussed below.

Table 4. Amount of $C d^{2+}$ Adsorbed by MCMWM

\begin{tabular}{|c|c|c|c|}
\hline $\begin{array}{l}\text { Cd concentration } \\
\text { before } \\
\text { adsorption } \\
(\mathrm{mg} / \mathrm{L})\end{array}$ & $\begin{array}{l}\mathrm{Cd} \text { concentration } \\
\text { after adsorption } \\
(\mathrm{mg} / \mathrm{L})\end{array}$ & $\begin{array}{l}\text { Amount of } \\
\mathrm{Cd} \text { adsorbed } \\
\text { per unit } \\
(\mathrm{mg} / \mathrm{kg})\end{array}$ & $\begin{array}{l}\text { Rate of } \mathrm{Cd} \\
\text { adsorbed } \\
(\%)\end{array}$ \\
\hline 20 & 1.12 & 188.8 & 94.4 \\
\hline 40 & 5.42 & 345.8 & 86.5 \\
\hline 80 & 19.26 & 607.4 & 75.9 \\
\hline 200 & 135.58 & 644.2 & 32.2 \\
\hline
\end{tabular}

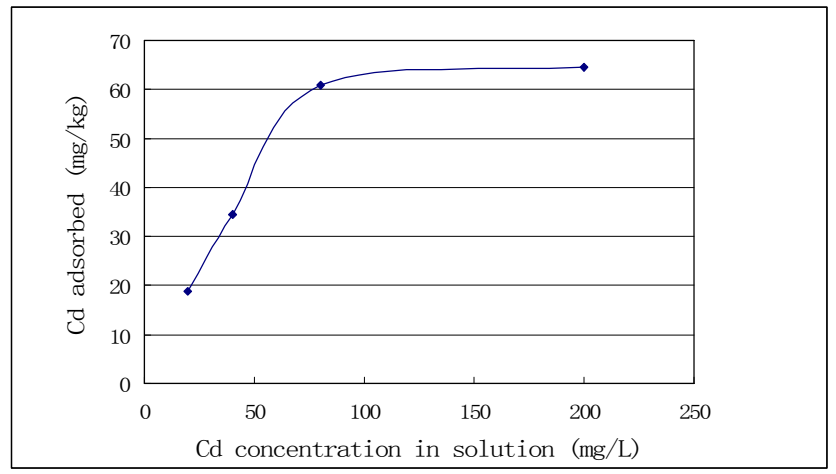

Figure 5. Amount of $\mathrm{Cd}^{2+}$ adsorbed versus $\mathrm{Cd}^{2+}$ concentration in solution.

\subsubsection{Adsorption Capacity}

The adsorption of $\mathrm{Cd}^{2+}$ was carried out to investigate the adsorption capacity of MCMWM on removal of heavy metals, and to deal with the affinity, selectivity and reactivity between adsorbents and adsorbates. A series of $\mathrm{Cd}^{2+}$ solutions of $20,40,80$ and $200 \mathrm{mg} / \mathrm{L}$ were prepared for the adsorption experiment in a short period of adsorption time, for example $0.5 \mathrm{hr}$. The total amount of $\mathrm{Cd}^{2+}$ adsorbed increased with increasing concentrations of $\mathrm{Cd}^{2+}$ in solution (Table 4, Figure 5). The amount of $\mathrm{Cd}^{2+}$ adsorbed per unit, calculated based on the amount adsorbed per kg solid MCMWM, also increased as the concentration of $\mathrm{Cd}^{2+}$ increased in solution (Table 4). However, the adsorption rate, derived from the fraction of $\mathrm{Cd}^{2+}$ adsorbed as a function of the initial concentration of $\mathrm{Cd}^{2+}$ in solution, decreased as the concentration of $\mathrm{Cd}^{2+}$ increased in solution. This might be due to the equilibrium formed between adsorption and desorption during the reaction period and the saturation of affinity sites on the MCMWM surfaces. The $\mathrm{Cd}^{2+}$ adsorption occurred rapidly once the MCMWM particles were suspended in solution. For the initial $\mathrm{Cd}^{2+}$ concentration of $20 \mathrm{mg} / \mathrm{L}$ treatment, the rate of adsorption reached up to as high as $94.4 \%$ within half an hour, indicating that affinity and selectivity for $\mathrm{Cd}^{2+}$ was high. This could be attributed to the charge, concentration, and $\mathrm{pH}$.

\subsubsection{Factors Influencing Cd2+ Adsorption}

A number of factors may affect $\mathrm{Cd}^{2+}$ adsorption on liquid-solid interface. Firstly, the surface charges have been reported to influence the selective adsorption. For instance, adsorbents carrying negative charges usually provide affinitive sites to adsorbates with positive charges [7]. Because most minerals present in MCMWM were 2:1 clay minerals, they usually carried negative charges that provided affinity and selectivity for adsorbing cations onto their surfaces. As a result, MCMWM attracted heavy metals with positive charges. Gerritse [18] and Hayes and Bolt [2] reported that negative charges on the surface of crystals induced adsorption of $\mathrm{Cd}^{2+}$ onto 2:1 clay minerals, which was in consistence with the results of the present work.

Secondly, a higher $\mathrm{Cd}^{2+}$ concentration can promote itself towards the adsorption direction, resulting in the increase of $\mathrm{Cd}^{2+}$ adsorbed (Table 4, Figure 5). This phenomenon has been observed by a number of researchers and such reactions have been reported to occur commonly in laboratory experiments [10] and in natural environmental systems [27-28]. An increase of $\mathrm{Cd}^{2+}$ concentration in solution could result not only in supplying abundant $\mathrm{Cd}^{2+}$ ions, as a consequence to increase the ionic strength in favoring $\mathrm{Cd}^{2+}$ adsorption, but also in desorbing $\mathrm{Cd}^{2+}$ from the surfaces already adsorbed $\mathrm{Cd}^{2+}$. The hypothetical model of $\mathrm{Cd}^{2+}$ adsorption can be described as the following. When a $\mathrm{Cd}^{2+}$ in solution is brought into contact with the surface, an activated complex is formed. This transition site can be identified as the configuration of the system at the peak of the potential energy barrier. The rate of reaction is the number of $\mathrm{Cd}^{2+}$ ions passing over the potential energy barrier per unit time [10]. As noticed in this experiment, $\mathrm{Cd}^{2+}$ adsorption reaction was rapid at the early stage of contact between $\mathrm{Cd}^{2+}$ and the affinitive sites of the MCMWM surfaces. In particular for $\mathrm{Cd}^{2+}$ adsorption at a lower concentration such as $20 \mathrm{mg} / \mathrm{L}$, the percentage of $\mathrm{Cd}^{2+}$ adsorption can reach to more than $90 \%$ within half an hour (Table 4).

Thirdly, the amount of $\mathrm{Cd}^{2+}$ adsorbed has been reported to be affected greatly by $\mathrm{pH}$ in solution $[2,9,12,29]$. The 
result of $\mathrm{Cd}^{2+}$ adsorption by MCMWM has also shown that the amount of $\mathrm{Cd}^{2+}$ adsorbed was $\mathrm{pH}$ dependent, increasing as $\mathrm{pH}$ values increased between 3 and 8 , with significant increases between 6 and 8 (Figure 6) [30-31]. Al-Hawas [14], and Gupta and Bhattacharyya [15] found that adsorption of $\mathrm{Cd}^{2+}$ by clay mineral is a function of $\mathrm{pH}$. Having the effect of organic acids, the percentage of $\mathrm{Cd}^{2+}$ adsorbed on mineral increased considerably with increasing $\mathrm{pH}$ of the solution [13]. In high acidic conditions, adsorption of $\mathrm{Cd}^{2+}$ may not be favorable, because $\mathrm{H}^{+}$could compete with $\mathrm{Cd}^{2+}$ to take up adsorption sites, thus reducing the amount of $\mathrm{Cd}^{2+}$ adsorbed. In contrast, a rapid increase in $\mathrm{Cd}^{2+}$ adsorption in an alkaline condition indicated that, when the $\mathrm{pH}$ value was increased, excrescent $\mathrm{OH}^{-}$can react with $\mathrm{Cd}^{2+}$ to produce hydrate deposition which can be adsorbed more readily by MCMWM. The increase in $\mathrm{pH}$ value was meant to increase $\mathrm{OH}^{-}$, which was equal to the addition of negative charges on the surface of MCMWM and the $\mathrm{OH}^{-}$acted as a bridge to improve the adsorptive characteristics of MCMWM.

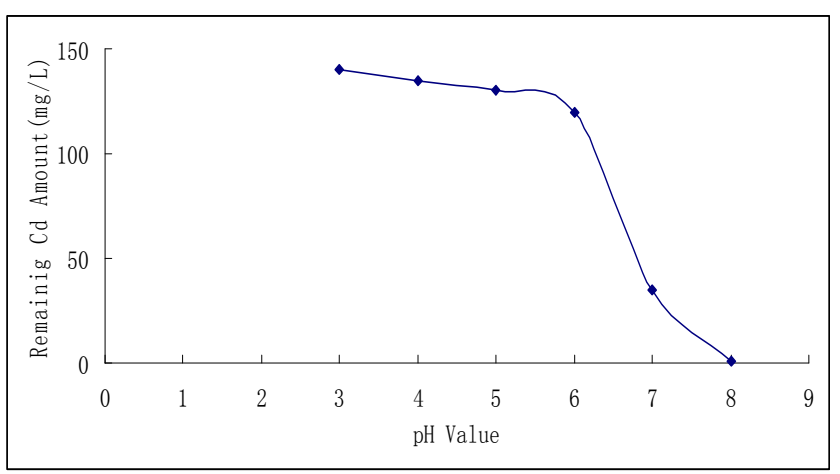

Figure 6. Amount of $\mathrm{Cd}^{2+}$ remaining in solution decreased with increasing pH.

\section{Conclusions}

The material used in this study was a modified clay mineral waste material (MCMWM) with capacity of adsorption optimized after modification. The physical, chemical and mineralogical characteristics were investigated in order to determine the relationships between adsorbent and adsorbate with the goal of using this material for removal of heavy metals.

The minerals present in MCMWM were mainly 2:1 clays, which usually carry negative charges that provide affinity and selectivity for heavy metal adsorption. The surface structure of MCMWM has been changed after modification. Particles of different sizes and shapes with surface defects, including rough surfaces, various edges, and different types of external and internal pores were observed. As found in a number of previous works, the capacity, affinity, selectivity, reactivity relating to adsorption depended largely on surface properties of a material. This relationship confirmed by this present work has added useful data to the interpretation of adsorption affected by surface properties. The toxicity of MCMWM was evaluated by chemical analysis of five targeted heavy metals. The results indicated that none of these five heavy metals exceeded the maximum allowed levels based on the Dutch Standard criteria. Thus MCMWM was suitable to be used as adsorbent for environmental remediation.

Cadmium ion adsorption by MCMWM exhibited an increasing trend as the concentration of $\mathrm{Cd}^{2+}$ increased in solution. The rate of $\mathrm{Cd}^{2+}$ adsorption in a concentration of $20 \mathrm{mg} / \mathrm{L}$ reached to $94.4 \%$ within half an hour. However, the adsorption rate revealed a decreasing trend as the concentration of $\mathrm{Cd}^{2+}$ in solution increased. This might be attributed to the equilibrium formed between adsorption and desorption that was influenced by the ionic strength, chemical composition, and the saturation of adsorption sites. Adsorption could be affected by affinity, selectivity, and reactivity. These factors were related largely to the surface structure and chemistry. Modified clay mineral waste material has shown a great capacity to adsorb $\mathrm{Cd}^{2+}$ up to $644 \mathrm{mg} / \mathrm{kg}$.

\section{Acknowledgement}

This work is financially supported by the Beijing Normal University-Hong Kong Baptist University, United International College (UIC) under a project No. R201208.

\section{References}

[1] Online Available: www.epd.gov.hk.

[2] M.H.B. Hayes, G.H. Bolt, Interactions at the Soil Colloid Soil Solution Interface (G.H. Bold et al., editors.), Soil colloids and the soil solution. pp.1-33, NATO Science Series E, Plenum, New York and London, 1990.

[3] J. Wen, H. Li, C.F. Di, C.S. Liang, L.B. Wang, "Risk assessment of Cadmium in food in Guangdong". South China Protection Medicine, Vol.24, pp.63-64 2008.

[4] A. Lindén, I. Olsson, I. Bensryd, T. Lundh, S. Skerfving, A. Oskarsson, "Monitoring of cadmium in the chain from soil via crops and feed to pig blood and kidney", Ecotoxicology and Environmental Safety, Vol.55, pp.213-222, 2003.

[5] M. Trzcinka-Ochocka, M. Jakubowski, G. Razniewska, T. Halatek, A. Gazewski, "The effects of environmental cadmium exposure on kidney function: the possible influence of age", Environmental Research, Vol.95, pp.143-150, 2004.

[6] T. Kawada, S. Suzuki, "A Review on the Cadmium Content of Rice, Daily Cadmium Intake, and Accumulation in the Kidneys", Journal of Occupational Health, Vol.4, pp.264-269, 2005.

[7] B.J. Alloway, Heavy Metals in Soils. 2nd Ed, Blackie Academic and Professional, London, 1995.

[8] Y.B. Zhang, "Research on adsorption of heavy metals by montmorillonite", Journal of Anhui Agricultural Sciences, Vol.29, pp.184-186, 2008

[9] A.C.C. Newman, M.H.B. Hayes, Soil Colloids and Their Associations in Aggregates (M.F. De Boodt, M.H.B. Hayes, A. Herbillon, E.B.A. De Strooper, and J.J. Tuck, editors.), Some properties of clays and of other soil colloids and their 
influences on soils, pp. 39-55, Plenum, New York and London, 1990.

[10] H.D. Ruan, R.J. Gilkes, "Kinetics of phosphate sorption and desorption by synthetic aluminous goethite before and after thermal transformation to hematite", Clay Minerals, Vol.31, pp.63-74, 1996.

[11] H.D. Ruan, R.J. Gilkes, "Dehydroxylation of aluminous goethite: unit cell dimensions, crystal size and surface area" Clays and Clay Minerals, Vol.43, pp.196-211, 1995.

[12] K.G. Tiller, J. Gerth, G. Brummer, "The adsorption of Cd, Zn and Ni by soil clay fractions: Procedures for partition of bound forms and their interpretation", Geoderma, Vol.34, pp.1-16, 1984.

[13] M. Liao, "Effects of organic acids on adsorption of cadmium onto kaolinite, goethite, and bayerite", Pedosphere, Vol.16, pp.185-191, 2006.

[14] I. Al-Hawas, "The impact of EC and pH on the adsorption of $\mathrm{Zn}$ and $\mathrm{Cd}$ by palygorskite mineral", European Journal of Scientific Research, Vol.24, pp.451-462, 2008.

[15] S.S. Gupta, K.G. Bhattacharyya, "Treatment of water contaminated with $\mathrm{Pb}(\mathrm{II})$ and $\mathrm{Cd}(\mathrm{II})$ by adsorption on kaolinite, montmorillonite and their acid-activated forms", Indian Journal of Chemistry Technology, Vol.16, pp.457-470, 2009.

[16] G. Brunauer, P.H. Emmett, E. Teller, “Adsorption of gases in multimolecular layers", Journal of the American Chemical Society, Vol.60, pp.309-319, 1938.

[17] H.D. Ruan, R.L. Frost, J.T. Kloprogge, "Comparison of Raman spectra in characterizing gibbsite, bayerite, diaspore and boehmite", Journal of Raman Spectroscopy, Vol.32, pp.745-750, 2001.

[18] R.G. Gerritse, "Column- and catchment-scale transport of cadmium: effect of dissolved organic matter", Journal of Contaminant Hydrology, Vol.22, pp.145-163, 1996.

[19] L.A.G. Aylmore, "Hysteresis in gas sorption isotherms", Journal of Colloid and Interface Science, Vol.46, pp.410-416, 1974.

[20] I.D. Sills, L.A.G. Aylmore, J.P. Quirk, "A pore size distribution analysis of illite-kaolinite mixtures", Soil Science, Vol.24, pp.480-490, 1973.

[21] I.D. Sills, L.A.G. Aylmore, J.P. Quirk, "A comparison between mercury injection and nitrogen sorption as methods of determining pore size distribution", Proceedings - Soil Science Society of America, Vol.37, pp.535-537, 1973.

[22] H.D. Ruan, R.J. Gilkes, "Specific surface area and pore size distribution of synthetic Al-goethite before and after thermal transformation to hematite", Clay Minerals, Vol.31, pp.75-79, 1996.

[23] F. Watari, J. van Landuyt, P. Delavignette, S. Amelinckx, "Electron microscopic study of dehydration transformations. I. Twin formation and mosaic structure in hematite derived from goethite", Journal of Solid State Chemistry, Vol.29, pp.137-150, 1979.

[24] F. Watari, P. Delavignette, J. van Landuyt, S. Amelinckx, "Electron microscopic study of dehydration transformations. Part III. High resolution observation of the reaction process $\mathrm{FeOOH} \rightarrow \mathrm{Fe}_{2} \mathrm{O}_{3}$ ", Journal of Solid State Chemistry, Vol.48, pp.49-64, 1983.

[25] H. Nano, R. Fujiwara, "Micropore formation due to thermal decomposition of acicular microcrystals of $\alpha$-FeOOH", Journal of Colloid and Interface Science, Vol.73, pp.406-415, 1980.

[26] J.L. Rendon, J. Cornejo, P. Dearambarri, C.J. Serna, "Pore structure of thermally treated goethite $(\alpha-\mathrm{FeOOH})$ ", Journal of Colloid and Interface Science, Vol.92, pp.508-516, 1983.

[27] H.D. Ruan, R.J. Gilkes, "Accumulation of phosphorus in farm ponds and dams in South-Western Australia", Journal of Environmental Quality, Vol.29, pp.1875-1881, 2000.

[28] N. Saleh, K. Sirk, T. Phenrat, B. Dufour, K. Matyiaszewski, R.D. Tilton, G.V. Lowry, "Surface modifications enhance nanoiron transport and NAPL targeting in saturated poruous media", Environmental Engineering Science, Vol.24, pp.45-57, 2007.

[29] C.Y. Fu, W. Dong, Y.Z. Lu, "Form of cadmium in soil and sediment and its effect on water system", Water Resource Protection, Vol.4, pp.25-28, 1996.

[30] Z.Q. Lin, "Adsorption of Cadmium ( II ) Ions and application of modified clay mineral waste material for removal of heavy metal from contaminated water", Honor Student Thesis. Beijing Normal University-Hong Kong Baptist University United International College, P.R. China, 2008.

[31] Y.N. Jiang, "Physical, Chemical and Mineralogical Properties of Modified Clay Mineral Waste Materials Relating to Cadmium Adsorption", Honor Student Thesis. Beijing Normal University-Hong Kong Baptist University United International College, P.R. China, 2009. 